\title{
Incidence and Significance of Iprodione-Insensitive Isolates of Botrytis squamosa
}

\author{
O. Carisse and D. M. Tremblay, Agriculture and Agri-Food Canada, 430 Gouin blv., St-Jean-sur-Richelieu, Québec, \\ J3B 3E6, Canada
}

\begin{abstract}
Carisse, O., and Tremblay, D. M. 2007. Incidence and significance of iprodione-insensitive isolates of Botrytis squamosa. Plant Dis. 91:41-46.

Botrytis leaf blight, caused by Botrytis squamosa, is an economically important disease of onion. The principal means of controlling the disease is by applying fungicides. Typical fungicide programs include applications of dithiocarbamates, chloronitriles, carboxamides, and dicarboximides such as iprodione (Rovral). Onion fields were surveyed in 2002, 2003, and 2004 for insensitivity to iprodione. Tests for insensitivity to iprodione were conducted on 62,58 , and 60 monoconidial field isolates using the automated quantitative (AQ) method with a discriminatory dose of $1.78 \mathrm{ppm}$ of iprodione active ingredient (a.i.) in 2002, 2003, and 2004, respectively. Overall, insensitive isolates were detected in $51 \%$ of the fields, and the proportions of insensitive isolates were $8.1,20.7$, and $18.3 \%$ in 2002,2003 , and 2004, respectively. The aggressiveness of 10 insensitive and 18 sensitive isolates and the efficacy of iprodione was tested in planta. Onion leaves were inoculated with $750 \mu \mathrm{l}$ of a conidial suspension of 75,000 conidia per ml and incubated in a growth chamber at $15^{\circ} \mathrm{C}$. Aggressiveness was measured as lesion density (average number of lesions per $\mathrm{cm}^{2}$ of onion leaf). Lesion density varied from 2.82 to 8.04 lesions per $\mathrm{cm}^{2}$ of leaf. There was a significant effect $(P<0.0001)$ of isolates on lesion density. However, there was no significant correlation between lesion density and sensitivity to iprodione $(r=$ 0.08 ). When onion leaves were sprayed with $1,875,3,750$, and $7,500 \mathrm{ppm}$ of iprodione, percent inhibition of lesion density was higher for sensitive isolates with means of 43.04, 61.42, and 74.59, respectively. Accordingly, percent inhibition was lower for insensitive isolates with means of $13.81,28.26$, and 44.37 for iprodione concentrations of $1,875,3,750$, and 7,500, respectively. It was concluded that the incidence of insensitive isolates was relatively low, but insensitive isolates were capable of infecting onion leaves. There was a good relationship between insensitivity to iprodione in $B$. squamosa populations measured in vitro with the AQ method, and the reduced efficacy of iprodione in controlling Botrytis leaf blight.
\end{abstract}

Botrytis leaf blight caused by Botrytis squamosa (Walker) is an important disease of onion in the United States and eastern Canada (1,5). During warm and moist summers, $B$. squamosa can partially defoliate the plants causing reduction in bulb size and consequent economic loss (1-3). Botrytis leaf blight is endemic, and as a consequence, growers tend to initiate their fungicide program at the fourth leaf stage or in mid-June for onion seeds sown in May. There are several tools for integrated management including methods to reduce inoculum (cultural or biological) and improved timing of fungicide sprays $(5,6)$. Initiation of fungicide programs could be done based on critical disease levels $(24,28)$, or on a critical inoculum level (5). Interval between sprays can be adjusted using forecasting systems $(11,30)$. Nevertheless, in eastern Canada, growers typically start their fungicide programs with a preventive fungicide, such as a dithiocar-

Corresponding author: O. Carisse

E-mail: carisseo@agr.gc.ca

Accepted for publication 14 July 2006.

DOI: 10.1094/PD-91-0041

(C) 2007 Department of Agriculture and AgriFood, Government of Canada bamate applied at 7- to 10-day intervals, followed by fungicides such as chloronitrile or iprodione often mixed with a dithiocarbamate depending on disease pressure. A common fungicide program for Botrytis leaf blight in eastern Canada involves 6 to 14 fungicide sprays per season, among which 3 to 4 sprays include iprodione applied in a fungicide mixture. As a consequence, populations of $B$. squamosa are exposed to repeated applications of fungicides, and it is expected that fungicide resistance will develop to certain of the fungicides (29).

Failure to control Botrytis leaf blight with dithiocarbamates was first reported in 1976 (12). It was concluded that insensitivity to dithiocarbamates was involved in control failure; however, there was no evidence that insensitivity was the sole cause of control failure. In a recent study, Tremblay et al. (29) reported that all isolates of $B$. squamosa from southwest Montreal onion fields $(n=35)$ were sensitive to mancozeb $\left(\mathrm{EC}_{50}\right.$ ranged from 3.36 to $12.97 \mu \mathrm{g} / \mathrm{ml}$ ). In their study conducted in 2000, Tremblay et al. (29) detected $11.4 \%$ of the isolates collected as iprodione-insensitive isolates $\left(\mathrm{EC}_{50} \geq 3.98\right.$ $\mu \mathrm{g} / \mathrm{ml}$ ). In 1982, Presly and Maude (19) reported that iprodione-insensitive isolates of B. squamosa could be readily obtained in vitro by growing the isolates on agar amended with 4 to $2,500 \mu \mathrm{g}$ of iprodione per ml.

Because insensitive isolates can be readily selected when fungal populations are exposed to site-specific fungicides such as dicarboximides (iprodione and vinclozolin), it is often recommended to use these fungicides mixed with multisite fungicides such as dithiocarbamates or chloronitriles for which development of resistance is not expected (13). In 1990, Lorbeer and Vincelli (13) reported that Botrytis leaf blight control was improved when dicarboximide fungicides were mixed with contact fungicides such as chloronitrile. In eastern Canada, most onion growers use this antiresistance strategy and mix iprodione with a dithiocarbamate fungicide (e.g., Dithane DG). Nevertheless, insensitivity to iprodione was detected (29). This detection raised several questions. Does the use of half rates of iprodione in conjunction with a dithiocarbamate fungicide stimulate the development of resistance? Are the iprodioneinsensitive isolates capable of infecting onion leaves? Are the iprodione-insensitive isolates detected from laboratory tests controlled on onion leaves by half and full rates of iprodione?

Because it is not expected that new fungicides will be registered in the near future, it is important to know the incidence of fungicide resistance as well as to study the significance of the insensitivity. Therefore, the objectives of this study were to: (i) evaluate the incidence of iprodioneinsensitive isolates in B. squamosa populations from Québec, (ii) evaluate the aggressiveness of iprodione-sensitive and -insensitive isolates of B. squamosa, and (iii) study the efficacy of iprodione in controlling B. squamosa on onion leaves inoculated with insensitive and sensitive isolates of B. squamosa.

\section{MATERIALS AND METHODS}

Incidence of iprodione-insensitive isolates of B. squamosa. During the summers of 2002, 2003, and 2004, onion leaves showing typical lesions of Botrytis leaf blight were collected in onion fields of 10 to 30 ha in the muck soil area, located 30 to $50 \mathrm{~km}$ southwest of Montreal, Québec, Canada. Fields were selected based on the grower's voluntary participation in the program and varied from year to year. Samples were brought to the laboratory, and each sample consisted of at least five blighted onion leaves. To enhance sporula- 
tion, blighted onion leaves were cut into pieces approximately $0.5 \mathrm{~cm}$ long, placed in a 90-mm-diameter petri dish on a moistened filter paper, and incubated on a laboratory bench at room temperature (20 to $25^{\circ} \mathrm{C}$ ) for 2 to 10 days. Single-conidium isolates were prepared following a modified version of the method described by Tremblay et al. (29). Conidia from each single lesion were collected by using a sterile cotton-tipped applicator and placed in a sterile $1.5-\mathrm{ml}$ tube containing $300 \mu \mathrm{l}$ of a sterile glycerol solution (5\%) amended with novobiocin $(100 \mu \mathrm{g} / \mathrm{ml}$; Sigma Chemical Co., St. Louis, MO, U.S.A.) and tetracycline $(50 \mu \mathrm{g} / \mathrm{ml}$, Sigma) to avoid bacterial contamination. Single-conidium cultures were prepared from these spore suspensions as previously described (29). The plates were incubated in the dark at $18.5^{\circ} \mathrm{C}$ until mature sclerotia were produced, within 4 to 6 weeks. Sclerotia were harvested, washed in a $1 \%$ sodium hypochlorite solution, and rinsed in sterile distilled water prior to incubation under UV lights (Sylvania F20T12/BLB, 310 to $420 \mathrm{~nm}$ ) as previously described (29). Sporulating sclerotia were directly soaked in potato dextrose broth (PDB; Difco Laboratories, Detroit, MI, U.S.A.) as an alternative to scraping the spores into a small tube before adding PDB (29).

An automated quantitative (AQ) assay $(20,29)$ was used to determine the frequency of iprodione-insensitivity of $B$. squamosa isolates. Rovral Fungicide Wettable Powder (Bayer CropScience Inc., Calgary, Alberta, Canada) was diluted in PDB to prepare stock solution of 2,500 ppm iprodione. These following concentrations were chosen as discriminatory doses based on published reports $(27,29)$. Fungicides were prepared by appropriate dilution of the stock solution in PDB. Each well of a sterile enzyme-linked immunosorbent assay (ELISA) microplate with 96 wells (MicroWell Plates, Nalge Nunc International, Rochester, NY, U.S.A.) was filled with $50 \mu \mathrm{l}$ of 20,000 conidia/ml solution and $50 \mu \mathrm{l}$ of the proper fungicideamended PDB solution to obtain final concentrations of $0.00,1.78,3.16$, and $5.62 \mathrm{ppm}$ iprodione. Each well was considered as a replication, and each treatment was replicated eight times. Absorbance was used as a measure of fungal growth and was calculated by subtracting the initial absorbance value from the value obtained after $72 \mathrm{~h}$ of incubation in the dark at $18.5^{\circ} \mathrm{C}$ and $90 \%$ relative humidity. Percent inhibition of each isolate at each fungicide concentration was calculated by dividing absorbance of the well for each treatment by the mean absorbance of the control treatment (no fungicides) for that isolate. Isolates with less than $50 \%$ inhibition at $1.78 \mathrm{ppm}$ of iprodione were considered as insensitive. For each of the 3 years that the isolates were collected, disease pressure was estimated based on probabil- ity of sporulation, a disease risk index commonly used in the management of Botrytis leaf blight. This index is calculated daily from temperature and relative humidity (11). The probability of sporulation varies from 0 to $100 \%$. A probability of $70 \%$ is considered to be a high risk for disease development (11). Each year, daily probability of sporulation was calculated from 1 June to 1 September, and the number of days with probability above $70 \%$ was used as an index of disease pressure.

Aggressiveness of iprodione-sensitive and -insensitive isolates of $\boldsymbol{B}$. squamosa. Onion seedlings (cv. Bastille) were produced in bedding plant trays (36 plugs). Each hole of the tray was filled with $40 \mathrm{~g}$ of general purpose peat-based growing medium Promix BX (Premier Horticulture Inc., Rivière-du-Loup, Québec, Canada). Seeded bedding plant trays were incubated for 4 to 5 weeks at $15^{\circ} \mathrm{C}$ and $70 \% \mathrm{RH}$ in a growth chamber (Conviron model \#E15, Controlled Environments Limited, Winnipeg, Manitoba) with a 16-h photoperiod provided by fluorescent and incandescent light bulbs placed $90 \mathrm{~cm}$ above seedlings until the onions reached the third leaf stage or cotyledon senescence stage (23). Sclerotia of B. squamosa were produced as described previously. Inoculum was prepared by soaking sporulating sclerotia in a $50-\mathrm{ml}$ tube containing $20 \mathrm{ml}$ of a $1 \%$ glycerol solution. The solution was agitated for $2 \mathrm{~min}$ and filtered through two layers of cheesecloth. Concentration was adjusted to 75,000 conidia/ml with a hemacytometer. Aliquots of $750 \mu \mathrm{l}$ were prepared in $1.5-\mathrm{ml}$ tubes with each conidial suspension and stored at $-20^{\circ} \mathrm{C}$ for up to 1 month until required for the inoculation.

For inoculation, each onion seedling was placed in a transparent plastic tower of $67 \mathrm{~cm}$ height and $155 \mathrm{~mm}$ diameter. Inoculations were accomplished by placing the nozzle of an airbrush atomizer (Badger Air-Brush Co., Model 350-F, Franklin Park, IL, U.S.A.) upright to a perforated plastic cover placed at the top of the inoculating tower. Each seedling was inoculated with the spore suspension at $172.4 \mathrm{kPa}$ using an airbrush compressor (Phantom 100 Createx Colors, East Granby, CT, U.S.A.). Immediately after inoculation, perforated covers were replaced by nonperforated ones to maintain a high level of humidity in the towers for the entire 48-h incubation period. Inoculated plants were kept in a plant growth chamber adjusted to $15^{\circ} \mathrm{C}, 16$-h photoperiod, and $70 \% \mathrm{RH}$. Typical lesions of $B$. squamosa were counted on the first (oldest) and second leaf. Height and diameter at the base of each leaf were measured using an electronic caliper. Leaf area was calculated using the formula of a cone surface. The experiment was set up as a complete randomized design with seven replicates. The entire experiment was conducted twice.
Efficacy of iprodione in controlling infection by sensitive and insensitive isolates of $\boldsymbol{B}$. squamosa. Onion seedlings were prepared as described above until onions reached the third leaf stage. Rovral Fungicide Wettable Powder (commercial formulation of iprodione) was suspended in distilled water to obtain final concentrations of $0,1,875,3,750$, and 7,500 ppm in a final volume of $710 \mu \mathrm{l}$ per treatment. These concentrations corresponded to half, full, and twice the field dose of $1.5 \mathrm{~kg} / \mathrm{ha}$ in 400 liters of water, as recommended on the label. Fungicide treatments were accomplished based on the inoculation method described previously. Each onion seedling was sprayed in a tower by placing the nozzle of an airbrush atomizer upright to the perforated plastic cover placed at the top. Each seedling was sprayed with the fungicide solutions at $172.4 \mathrm{kPa}$. Immediately after treatment, the perforated covers were replaced by nonperforated ones, and the plants were incubated for $24 \mathrm{~h}$ in a growth chamber at $15^{\circ} \mathrm{C}, 16$-h photoperiod, and $70 \% \mathrm{RH}$. After incubation, plants were inoculated with 75,000 conidia of $B$. squamosa per $\mathrm{ml}$ with the same protocol as described previously. Plants were returned to the growth chamber until evaluation of the symptoms, which was accomplished as described previously. Inhibition in lesion density was calculated by dividing the number of lesions per $\mathrm{cm}^{2}$ of leaf obtained on fungicide-sprayed plants by the number of lesions per $\mathrm{cm}^{2}$ of the control (sprayed with water). The experiment was arranged as a complete randomized design with four replicates. The entire experiment was conducted twice.

Data analysis. Pearson correlation coefficient was used to determine the degree of association between the proportion of the iprodione-insensitive isolates and number of days with probability of sporulation by B. squamosa above $70 \%$. For all experiments, homogeneity of variance ( $F$ test) was used to determine whether the data from the experimental runs could be pooled. Analysis of variance (ANOVA) was used to test the significance of isolates on the number of lesions per $\mathrm{cm}^{2}$ of onion leaf. Multiple comparison test (LSD) was used to detect significant differences among means at the 0.05 confidence level (26). Spearman correlation coefficient between lesion density and iprodione sensitivity (sensitive versus insensitive isolates) was used to determine the degree of association between sensitivity to iprodione and lesion density. Statistical analyses were conducted using the SAS software program (SAS Institute Inc., version 9.1, Cary, NC, U.S.A.).

\section{RESULTS}

Incidence of iprodione-insensitive isolates of $\boldsymbol{B}$. squamosa. Surveys for iprodione-insensitivity were conducted on 10,13 , and 12 farms in 2002, 2003, and 
2004, respectively (Table 1). From all samples collected in the field, 1 to 20 single-conidial isolates per field were obtained for a total of 62,58 , and 60 in 2002, 2003, and 2004, respectively (Table 1). The proportion of insensitive isolates was $8.1,20.7$, and $18.3 \%$ in 2002,2003 , and 2004, respectively (Fig. 1). Overall, for the 3 years of the survey, at least one insensitive isolate was found in 40,54 , and $58 \%$ of the fields in 2002, 2003, and 2004, respectively, with an overall mean of $51 \%$ for the 3 years (Table 2). There was a significant correlation between the proportion of insensitive isolates and the number of days with a probability of sporulation by $B$. squamosa above $70 \%$ ( $r=0.98, P=0.0064)$.

Aggressiveness of iprodione-sensitive and -insensitive isolates of $B$. squamosa. Data from the two experimental runs were pooled based on homogeneity of variance $(P>0.05)$. There was a significant effect $(P<0.0001)$ of isolate on lesion density (number of lesions per $\mathrm{cm}^{2}$ of onion leaf). Lowest lesion density was 2.82 obtained with isolate $31 \mathrm{R} 01$, while isolate 18R6 resulted in the highest lesion density of 8.04 lesions per $\mathrm{cm}^{2}$ of leaf (Fig. 2). The ratio of lesion density of the most aggressive and the least aggressive isolates of $B$. squamosa was 2.85. Despite this large difference in aggressiveness, there was no significant correlation between lesion density and sensitivity to iprodione $(r=0.08$, $P=0.6667)$. Among the most aggressive isolates, three (10A6, 10A31, and 18R6) were insensitive to iprodione, while six insensitive isolates (13R09, 13R02, 34R03, 10A17, 29R01, and 29R02) were among the least aggressive isolates (Fig. 2).

Efficacy of iprodione in controlling infection by sensitive and insensitive isolates of $\boldsymbol{B}$. squamosa. Data from the two experimental runs were pooled based on homogeneity of variance $(P>0.05)$. There was a significant effect of isolate and fungicide concentration on inhibition of lesion density $(P<0.0001)$. When onion leaves were sprayed with Rovral at a concentration of $1,875,3,750$, and 7,500 ppm, there was a significant isolate effect on percent inhibition of lesion density $(P<0.0001)$. At all fungicide concentrations, percent inhibition of lesion density was higher for sensitive isolates with means of 43.04, 61.42 , and $74.59 \%$ for concentrations of $1,875,3,750$, and 7,500, respectively (Fig. 2). Accordingly, percent inhibition of lesion density was lower for insensitive isolates with means of $13.81,28.26$, and $44.37 \%$ for concentrations of $1,875,3,750$, and 7,500, respectively (Fig. 2). The ratios of mean lesion density inhibition between sensitive and insensitive isolates were $3.12,2.17$, and 1.68 for concentrations of $1,875,3,750$, and 7,500 , respectively.

\section{DISCUSSION}

Fungicides are routinely used for Botrytis leaf blight management in onion pro- duction. However, no dramatic disease management failures have been documented, and monitoring for efficacy and relative control achieved by different fungicides has not been accomplished in Québec. Consequently, the use of fungicides prone to resistance continues to be widespread in Québec. This study was initiated, in part, to address growers' concerns regarding the incidence and significance of iprodione-insensitive isolates of B. squamosa in the most important onion production area of Québec (southwest of Montreal). In the present study, the proportion of insensitive isolates varied from year to year, with $8.1,20.7$, and $18.3 \%$ in 2002 , 2003 , and 2004, respectively. These results are similar to those reported for a survey conducted in 2000 , in which $11.4 \%$ of the isolates were insensitive to iprodione (29). In the present study, insensitive isolates were detected in about half of the fields surveyed. For the 4 years of surveys, there was a significant correlation between the proportion of insensitive isolates and the number of days with a probability of sporulation by $B$. squamosa above $70 \%$. In other words, more insensitive isolates were detected during seasons with higher disease pressure. This phenomenon could be explained, at least in part, by the selection pressure. If growers apply more fungicides during years more favorable to disease development, it is expected that the population of insensitive isolates will be higher. However, growers tend to apply fungicides regularly based on a calendar rather than on disease pressure. This phenomenon could also be explained by the lower fitness of the iprodione-insensitive isolates (22). Under weather conditions less conducive to $B$. squamosa epidemics, insensitive isolates might be less capable than sensitive ones of infecting onion leaves or, because their survival ability is lower, they can initiate epidemics with smaller amounts of inoculum and hence epidemics are delayed.

Fitness of fungicide insensitive isolates is an important consideration in antiresistance management strategies. If fitness costs are coupled with fungicide resistance, the frequency of resistant isolates is expected to decline in the absence of the fungicide. In this situation, if application of the fungicide is discontinued, it would be expected that the frequency of fungicide-insensitive isolates would decline (25). Several parameters could be used to assess fitness, including those associated to the pathogenic phases of the pathogen life cycle such as lesion production, growth rate, and rate of sporulation and those not associated with pathogenic phase such as

Table 1. Incidence of iprodione-insensitive isolates of Botrytis squamosa collected in onion fields in southwest Montreal from 2002 to 2004

\begin{tabular}{|c|c|c|c|c|}
\hline Year & Grower & $\begin{array}{c}\text { Number of } \\
\text { sampled fields }\end{array}$ & $\begin{array}{l}\text { Number of } \\
\text { isolates }\end{array}$ & $\begin{array}{c}\text { Number of } \\
\text { insensitive isolates }\end{array}$ \\
\hline \multirow[t]{10}{*}{2002} & $\mathrm{AB}$ & 1 & 1 & 1 \\
\hline & $\mathrm{AF}$ & 2 & 3 & 0 \\
\hline & $\mathrm{AR}$ & 3 & 14 & 1 \\
\hline & AV & 2 & 5 & 1 \\
\hline & $\mathrm{EC}$ & 2 & 6 & 0 \\
\hline & $\mathrm{EF}$ & 1 & 1 & 0 \\
\hline & $\mathrm{OB}$ & 2 & 5 & 2 \\
\hline & UA & 2 & 20 & 0 \\
\hline & UG & 1 & 5 & 0 \\
\hline & UN & 1 & 2 & 0 \\
\hline \multirow[t]{13}{*}{2003} & $\mathrm{AB}$ & 2 & 4 & 1 \\
\hline & AV & 1 & 2 & 1 \\
\hline & EB & 2 & 4 & 0 \\
\hline & EC & 2 & 10 & 0 \\
\hline & IA & 1 & 5 & 2 \\
\hline & LG & 1 & 8 & 2 \\
\hline & MD & 1 & 2 & 1 \\
\hline & MP & 2 & 4 & 2 \\
\hline & PR & 1 & 2 & 0 \\
\hline & SC & 1 & 7 & 0 \\
\hline & UA & 1 & 1 & 0 \\
\hline & UJ & 1 & 2 & 0 \\
\hline & UN & 2 & 7 & 3 \\
\hline \multirow[t]{12}{*}{2004} & $\mathrm{AB}$ & 1 & 2 & 0 \\
\hline & $\mathrm{AF}$ & 2 & 6 & 2 \\
\hline & $\mathrm{AR}$ & 1 & 4 & 3 \\
\hline & EB & 1 & 2 & 1 \\
\hline & EC & 3 & 8 & 0 \\
\hline & ED & 5 & 18 & 2 \\
\hline & $\mathrm{EF}$ & 2 & 4 & 0 \\
\hline & SC & 1 & 3 & 1 \\
\hline & SU & 3 & 5 & 1 \\
\hline & TI & 1 & 1 & 1 \\
\hline & UF & 1 & 1 & 0 \\
\hline & UJ & 2 & 6 & 0 \\
\hline
\end{tabular}


survival (22). In the present study, we examined lesion production as a component of fitness. Lesion density varied from 2.8 to 8.0 lesions per $\mathrm{cm}^{2}$ for the 28 isolates assayed. However, there was no correlation between sensitivity to iprodione and lesion production. These results are similar to those reported for Botrytis cinerea by Raposo et al. (21), where fitness cost was measured as the rate of lesion growth and the rate of sporulation. However, when survival ability of sclerotia or mycelium of $B$. cinerea was studied, there was a significant $(P<0.05)$ negative correlation between survival of sclerotia and resistance to iprodione at least for some samplings dates, indicating that sclerotia of resistant isolates may not survive as well as sclerotia from sensitive isolates (22). When a similar experiment was conducted with mycelial growth, no relationship between survival and resistance was detected (22). Fitness costs in B. squamosa associated with fungicide resistance have not been previously studied, although there are several reports for $B$. cinerea $(8,16,21)$ and other fungal pathogens $(9,10,15$, 17,18). Depending on the pathogen and fungicide studied, the published results indicate that a fitness cost may or may not occur. Resistance to benzimidazole and dicarboximide was associated with reduced sporulation by resistant isolates of $B$. cinerea (8). Other researchers reported that there were no differences between fungicide-sensitive and fungicide-insensitive phenotypes based either on disease progress curves (16) or on lesion growth and sporulation rates (21). These contradictions could be explained by the relatively small number of isolates often used in those studies and also because fitness differences between insensitive and sensitive isolates most likely were caused by differences in the genetic background of the isolates rather than fitness costs (18). Other factors of fitness will have to be examined to resolve these differences. However, from the results of the present study, it is expected that insensitive isolates are capable of causing lesions on onion leaves at least under optimal conditions. The higher proportion of insensitive isolates obtained during seasons with higher disease pressure might be explained by a more narrow environmental requirement for infection by insensitive isolates.

Field resistance is often difficult to demonstrate because several factors may influence fungicide efficacy, including fungicide mixture preparation, spraying conditions (mainly wind), leaf coverage, and timing of application. Most often, fungicide resistance is detected based on laboratory tests (4). However, these tests must be correlated to fungicide efficacy. In this study, sensitive and insensitive isolates of $B$. squamosa were inoculated on onion leaves and exposed to half, full, and twice the recommended dose of iprodione. These doses were selected because it was anticipated that the volume of water used in a spray application would vary from one grower to another within the range of the spray volume recommended. Therefore, the B. squamosa isolates could be exposed to different concentrations of iprodione. At an iprodione concentration of 3,750 ppm, the mean lesion density inhibition was $61 \%$ for the sensitive isolates, while it was only $28 \%$ for the insensitive isolates. If this relationship applies to field situations,

Table 2. Relationship between the number of days with high probability of sporulation by Botrytis squamosa and incidence of iprodione-insensitive isolates

\begin{tabular}{lccc}
\hline Years & $\begin{array}{c}\text { Number of days } \\
\text { with probability } \\
\text { of sporulation } \mathbf{7 0 \%}^{\mathbf{a}}\end{array}$ & $\begin{array}{c}\text { Number of } \\
\text { isolates }\end{array}$ & $\begin{array}{c}\text { Insensitive } \\
\text { isolates } \\
(\boldsymbol{\%})\end{array}$ \\
\hline $2000^{\mathrm{b}}$ & 16 & 35 & 11.4 \\
2002 & 14 & 62 & 8.1 \\
2003 & 27 & 58 & 20.7 \\
2004 & 25 & 60 & 18.3 \\
\hline
\end{tabular}

${ }^{a}$ Probability of sporulation was calculated from the model developed by Lacy and Pontius (11), where the probabilities vary from 0 to $100 \%$.

b Data from previous report (29).

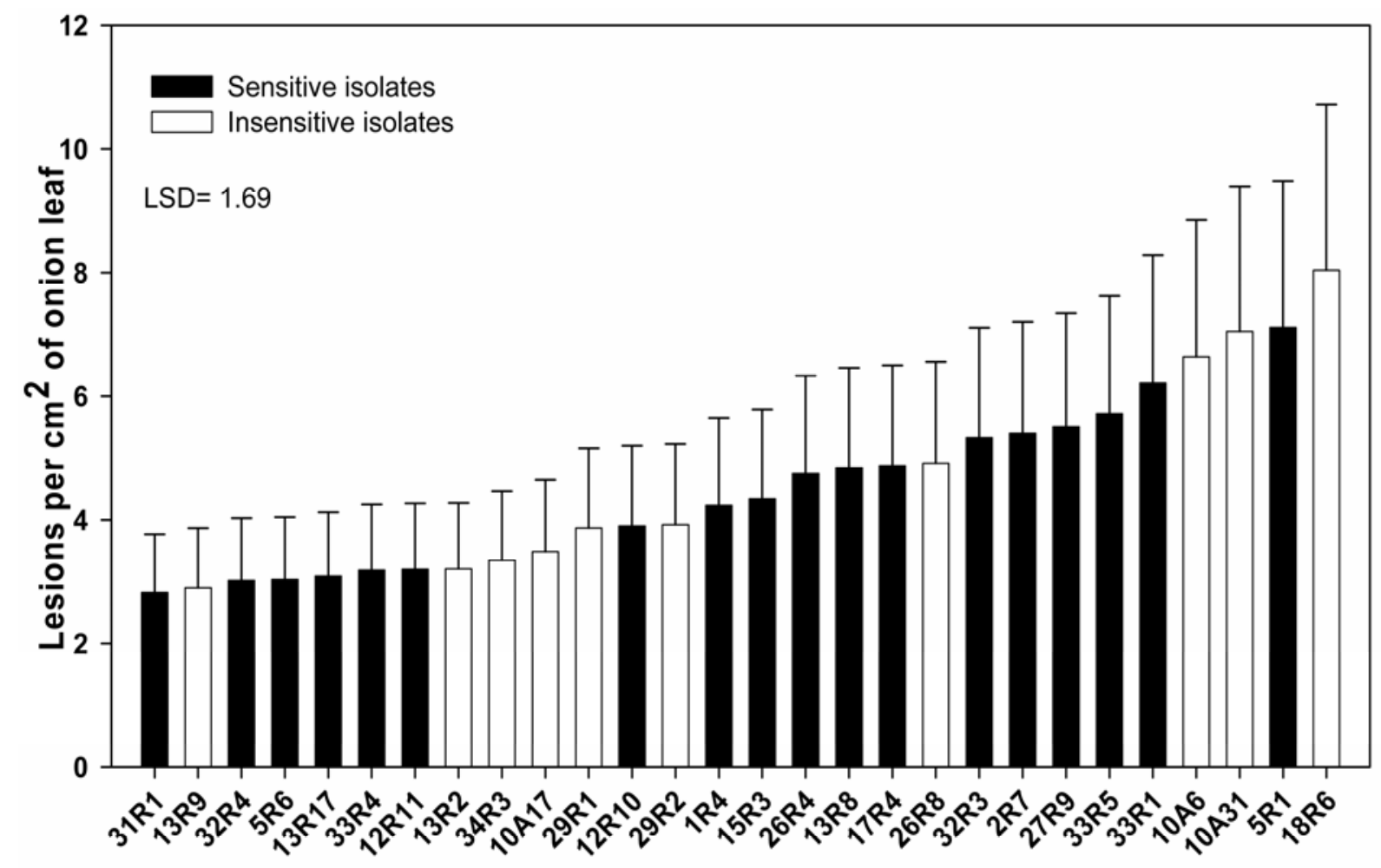

Isolates

Fig. 1. Aggressiveness of iprodione-insensitive and -sensitive isolates of Botrytis squamosa. 
iprodione efficacy will be reduced in the presence of insensitive isolates. There are conflicting reports on the ability of dicarboximide-resistant isolates, especially in vitro derived isolates, to cause disease on dicarboximide-sprayed plants $(7,14,19,25)$. Presly and Maude (19) reported that when applied to onion leaves, iprodione controlled the in vitro-produced iprodioneinsensitive isolates of B. squamosa inoculated on onion leaves. In their study, iprodione-insensitive isolates readily in- fected onion leaves, but conidial production from the lesions produced was lower than when iprodione-sensitive isolates were utilized (19). It is likely that different spray programs influence iprodione effectiveness in the presence of insensitive isolates. In the onion production area of southwest Montreal, it is a common practice to initiate the fungicide program against Botrytis leaf blight with a preventive fungicide, such as mancozeb applied on a 7- to 10-day interval, followed by

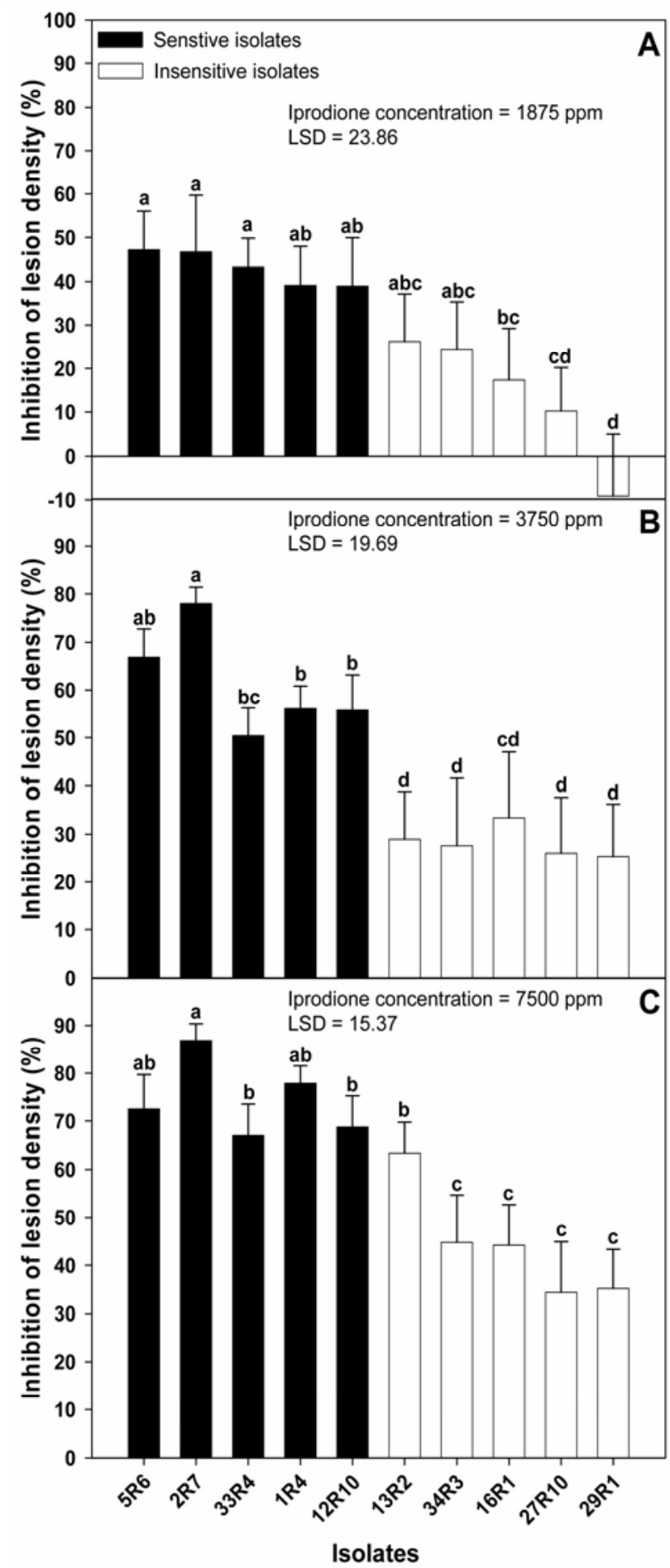

Fig. 2. Efficacy of half (A), full (B), and twice (C) the recommended dose of Rovral in controlling iprodione-insensitive and -sensitive isolates of Botrytis squamosa.

fungicides such as iprodione mixed with a dithiocarbamate when disease pressure increases. In this spray program, a half rate of Rovral is often used. The results of the present study clearly show that iprodioneinsensitive isolates of $B$. squamosa were not controlled by a half rate $(1,875 \mathrm{ppm})$ of Rovral. At this rate, inhibition was only $11 \%$ for insensitive isolates compared with $42 \%$ for the sensitive ones.

In our study, we identified relatively low frequencies of dicarboximide resistance in populations of $B$. squamosa from onion fields in southwest Montreal. Over the 4 years of the survey, we observed a trend toward increased frequencies of insensitive isolates. However, 4 years is not enough to detect a trend. Monitoring for iprodioneinsensitivity should be continued. Because there was a good correlation between resistance detected from laboratory assays and the failure of iprodione to protect onion leaves, it was concluded that the laboratory test is a good estimator of field resistance. However, such tests based on isolation and preparation of monoconidial isolates are time-consuming and expensive. A test based on molecular detection of mutation site would probably be more appropriate for long-term monitoring.

Recommendations to mix Rovral with a fungicide from another fungicide class, generally a dithiocarbamate, were introduced several years ago and probably explain, at least in part, the low frequency of iprodione-insensitive isolates detected in this study. Alternation of fungicides from different classes will be facilitated with new fungicides recently registered for management of Botrytis leaf blight. In addition to these fungicide antiresistance strategies, recommendations for managing Botrytis leaf blight should emphasize the use of integrated disease management practices that include forecasting systems, airborne inoculum detection, and biological control $(5,6)$.

\section{ACKNOWLEDGMENTS}

The authors are grateful to Caroline Roy, Daniel Rolland, Annie Lefebvre, Jean-Francois Desteredjian, and Nadia Surdek as well as all the summer students and the scouts working at the PRISME consortium for their technical assistance. This work was financially supported by a Matching Investment Initiative between Agriculture and Agri-Food Canada, the PRISME Consortium, and La Fédération des Producteurs Maraîchers du Québec.

\section{LITERATURE CITED}

1. Alderman, S. C., Biernbaum, J. A., Hoffhines, M., Timberlake, D. M., Welch, D. P., Lacy, M. L., and Barr, R. O. 1987. A simulation model of the spread of Botrytis leaf blight of onion and its effect on onion yields. Agric. Ecosyst. Environ. 19:55-70.

2. Baker, R. S., and Wilcox, G. E. 1961. Effect of foliage damage and stand reduction on onion yield. J. Am. Soc. Hortic. Sci. 78:400-405.

3. Boivin, G., and Sauriol, P. 1984. Dispersion statistics and sequential sampling plan for leaf blight caused by Botrytis squamosa in onion. Phytopathology 74:1385-1387.

4. Brent, K. J., and Hollomon, D. W. 1998. Fun- 
gicide Resistance: The Assessment of Risk. FRAC Monogr. No. 2. Global Crop Protection Federation, Brussels, Belgium.

5. Carisse, O., McCartney, H. A., Gagnon, J. A., and Brodeur, L. 2005. Quantification of airborne inoculum as an aid in the management of leaf blight of onion caused by Botrytis squamosa. Plant Dis. 89:726-733.

6. Carisse, O., Rolland, D., and Tremblay, D. M. 2006. Effect of Microsphaeropsis ochracea on production of sclerotia-borne and airborne conidia of Botrytis squamosa. Biocontrol 51:107126.

7. Gouot, J. M. 1988. Characteristics and population dynamics of Botrytis cinerea and other pathogens resistant to dicarboximide. Pages 53-55 in: Fungicide Resistance in North America. C. J. Delp, ed. American Phytopathological Society, St. Paul, MN.

8. Hsiang, T., and Chastagner, G. A. 1991. Growth and virulence of fungicide-resistant isolates of three species of Botrytis. Can. J. Plant Pathol. 13:226-231.

9. Kadish, D., and Cohen, Y. 1988. Fitness of Phytophthora infestans isolates from metalaxyl-sensitive and -resistant populations. Phytopathology 78:912-915.

10. Kadish, D., and Cohen, Y. 1992. Overseasoning of metalaxyl-sensitive and metalaxylresistant isolates of Phytophthora infestans in potato tubers. Phytopathology 82:887-889.

11. Lacy, M. L., and Pontius, G. A. 1983. Prediction of weather-mediated release of conidia of Botrytis squamosa from onion leaves in the field. Phytopathology 73:670-676

12. Lorbeer, J. W., and Ellerbrock, L. A. 1976. Failure of ethylene bisdithiocarbamates to control Botrytis leaf blight of onion. Proc. Am. Phytopathol. Soc. 3:75-84.
13. Lorbeer, J. W., and Vincelli, P. C. 1990. Efficacy of dicarboximide fungicides and fungicide combinations for control of Botrytis leaf blight of onion in New York. Plant Dis. 74:235-237.

14. Lorenz, G. 1988. Dicarboximide fungicide: History of resistance development and monitoring methods. Pages 45-51 in: Fungicide Resistance in North America. C. J. Delp, ed. American Phytopathological Society, St. Paul, $\mathrm{MN}$.

15. Merida, C. L., and Loria, R. 1994. Comparison of thiabendazole-sensitive and -resistant Helminthosporium solani isolates from New York. Plant Dis. 78:187-192.

16. Moorman, G. W., and Lease, R. J. 1992. Benzimidazole- and dicarboximide-resistant Botrytis cinerea from Pennsylvania greenhouses. Plant Dis. 76:477-480.

17. Peever, T. L., and Milgroom, M. G. 1993. Genetic correlations in resistance to sterol biosynthesis-inhibiting fungicides in Pyrenophora teres. Phytopathology 83:1076-1082.

18. Peever, T. L., and Milgroom, M. G. 1994. Lack of correlation between fitness and resistance to sterol biosynthesis-inhibiting fungicides in Pyrenophora teres. Phytopathology 84:515519.

19. Presly, A. H., and Maude, R. B. 1982. Tolerance in Botrytis squamosa to iprodione. Ann. Appl. Biol. 100:117-127.

20. Raposo, R., Colgan, R., Delcan, J., and Melgarejo, P. 1995. Application of an automated quantitative method to determine fungicide resistance in Botrytis cinerea. Plant Dis. 79:294296.

21. Raposo, R., Delcan, J., Gomez, V., and Melgarejo, P. 1996. Distribution and fitness of isolates of Botrytis cinerea with multiple fungi- cide resistance in Spanish greenhouses. Plant Pathol. 45:497-505.

22. Raposo, R., Gomez, V., Urrutia, T., and Melgarejo, P. 2000. Fitness of Botrytis cinerea associated with dicarboximide resistance. Phytopathology 90:1246-1249.

23. Rey, C., Stahl, J., Antonin, P., and Neury, G. 1974. Stades repères de l'oignon de semis. Rev. Suisse Vitic. Arboric. Hortic. 6:101-104.

24. Shoemaker, P. B., and Lorbeer, J. W. 1977. Timing initial fungicide application to contro Botrytis leaf blight epidemics on onions. Phytopathology 67:409-414.

25. Staub, T. 1991. Fungicide resistance: Practica experience with antiresistance strategies and the role of integrated use. Annu. Rev. Phytopathol. 29:421-442.

26. Steel, R. G. D., and Torrie, J. H. 1980. Principles and Procedures of Statistics, A Biometrical Approach. 2nd ed. McGraw-Hill Book Co. New York.

27. Stehmann, C., and De Waard, M. A. 1996 Sensitivity of populations of Botrytis cinerea to triazoles, benomyl and vinclozolin. Eur. J. Plant Pathol. 102:171-180.

28. Sutton, J. C., James, T. D. W., and Rowell, P. M. 1986. BOTCAST: A forecasting system to time the initial fungicide spray for managing Botrytis leaf blight of onions. Agric. Ecosyst. Environ. 18:123-143.

29. Tremblay, D. M., Talbot, B. G., and Carisse, O. 2003. Sensitivity of Botrytis squamosa to different classes of fungicides. Plant Dis. 87:573578.

30. Vincelli, P. C., and Lorbeer, J. W. 1989. BLIGHT-ALERT: A weather-based predictive system for timing fungicide applications on onion before infection periods of Botrytis squamosa. Phytopathology 79:493-498. 